\title{
The Rhetorical Moves in Indonesian EFL Graduate Students' Thesis Abstracts
}

\author{
Erma Sujiyani ${ }^{1^{*}}$
}

${ }^{1}$ The University of Palangka Raya, Central Kalimantan, Indonesia

\begin{abstract}
Rhetoric in an abstract writing literally means the techniques a writer might use to deliver complicated information in a limited amount of space effectively and intentionally. However, as being non-native speaking (NNS) writers, Indonesian EFL Graduate students often have difficulties in producing, organizing, and delivering ideas of an abstract into widely accepted international standard of English academic writing conventions. This study describes the nature and characteristics of the rhetoric of thesis abstract focusing on the moves-step(s) written by Indonesian EFL Graduate Students of Palangka Raya University. The model proposed by Samraj (2002) consisting of five moves: Move 1- Situating the Research, Move 2-Purpose, Move 3-Methods, Move 4-Results, and Move 5-Conclusion was used as a general guideline to analyze the movesstep(s) of the abstracts. The findings of the study show that three textual spaces: M2-Purpose, M3Methods, and M4-Results are compulsory while the other two (M1-Situating the Research and M5Conclusion) are optional; and the rhetorical pattern mostly employed in the abstracts is PMRC or M2-M3-M4-M5. However, in realizing the rhetorical strategies of the abstracts, a great deal of first language rhetorical interference (such as redundancy use of steps particularly in M2, reordering or non-linear patterns of steps mostly the steps in M3, the overlap function between moves especially between M4 and M5, the low occurrence of M1, and the repeated use of embedding moves particularly the embedment of M2 and M3) is discovered among the moves or the steps forming each move.
\end{abstract}

Keywords: rhetoric, moves-steps, thesis abstracts

\section{INTRODUCTION}

Learning to write in academic disciplines, especially in English academic writing, is an unavoidable challenge for most EFL (English as a Foreign Language) students from any different level of education, particularly the students of graduate programs. In partial fulfillment of the requirements for a certain degree in the higher level of education, they must be able to produce an academic writing product which should follow the conventions of English academic writing. This is a problematic matter for them; as being non-native speaking (NNS) writers, they often have difficulties in producing, organizing, and delivering ideas into widely accepted international standard of English academic writing conventions. They, as graduate students, are supposed to have the ability to organize and present messages/ideas in an intelligible writing form; however, in reality, they tend to experience serious problems in producing a desired piece of written text which is developed logically and analytically. In this case, their problem deals with rhetoric in writing.

Rhetoric in writing literally means the art of writing effectively. It refers to all the techniques a writer might use to influence readers and modify their understanding of a subject. It includes the practical skill of delivering a well-constructed theoretical science of

*Corresponding author: esyanio2@gmail.com

To cite this article: Sujiyani, E. (2022). The Rhetorical Moves in Indonesian EFL Graduate Students' Thesis Abstracts. Ebony --- Journal of English Language Teaching, Linguistics, and Literature, 2 (1) 2022, pp. 55--71. 
formulating rules and conditions for a good and balanced exposition (Wahab, 1986:88); or referring to Kaplan's opinion (1987:15), rhetoric is "the method of organizing syntactic units into larger patterns". Involving the terms "art, skill, techniques, and method" of writing, rhetoric has drawn many researchers' interest in conducting their studies and analysis on it. Therefore, a great amount of studies on the rhetoric of academic writing concerning different sections has been done increasingly in recent years, such as on the Introduction section (Basthomi, 2006a; Samraj, 2002, 2008; Swales, 1981, 1990; Zeng, 2009); on the Abstract section (Anderson, et al., 1997; Basthomi, 2006b; Djuwari, 2009; Dong and Xue, 2010; Junining, 2003; Martin, 2003; Melander, et al., 1997; Pho, 2008; Salager-Meyer, 1990, 1992; Samraj, 2005); and few studies focusing on the Discussion section (Dudley-Evans, 1997; Holmes, 1997; Peacock, 2002). From the examples of studies aforementioned, the rhetoric of an abstract attracts particular attention from many researchers.

Why are many researchers interested in studying the rhetoric of an abstract? What is interesting in an abstract? No one denies that an abstract is a highly condensed form of academic writing, and what is mostly agreed upon by the majority about an abstract is that it is a short document. It is a brief representation of a larger document. Normally, it is written in no more than one page and positioned on the beginning page or initial part of textbooks, papers, journals, theses, or dissertations. It stands alone preceding the whole content of the document and usually becomes the first thing seen or sought by readers. It plays an important role as a filtering device (Johnson, 1995) or a time saving device (Graetz, 1985). As a filtering device, it is used by researchers and academics to filter the existing literature when conducting research into a certain topic or when trying to keep upto-date with the latest advances in their field of interest. While as a time saving device, it helps the readers to decide on the relevance of the paper for his/her interests, so that it can be regarded worth reading, scanning or discarding.

The other role an abstract has is as a summary or a replacement for an entire document (Cleveland, 1983), or using Rathbone's term (1985, as cited in Basthomi, 2006 b), it is a "report in miniature". It is the representation or the summary of the whole writing which concisely highlights or reviews the major sections and elements covered along with the content and scope of the writing, and used to express the main claim and argument of an academic writing. An abstract can also function as a "map" which shows readers, who are willing to read the entire document, the writer's clear and informative argument or discussion and their locations to be covered in the document. Its function as a map will be failed being fulfilled if an abstract is poorly-written. A poorly-written abstract will not be able to capture the interest of potential readers who are eager to know further the exact content of the whole document. It may also confuse the readers as they do not know what to expect in the document. It fails in delivering the gist of the document to the readers. The readers might find any information outside of the associated document that should not be included in an abstract; or they might have wrong understanding and conception on the information conveyed in it.

To be able to achieve the above mentioned functions and roles, an abstract should be effectively and intentionally written. A clear and concise writing style that conveys 
complicated information (such as the purpose, method, result, and conclusion of the whole writing) must be able to be delivered in a limited amount of space. To do so, a certain skill or technique of writing (rhetoric) is absolutely needed. That is why studying an abstract writing is very interesting, as it will study certain skill and technique used by a writer to put, combine and arrange words into logical and analytical sentences which build larger featured patterns into an accurate, brief, and clear document called an abstract.

Considering the background of the study above, the present study is conducted to provide answers for the following general question: "How is the rhetoric of master's thesis abstracts realized by Indonesian EFL graduate students of English Language Education at Palangka Raya University?”

\section{METHOD}

The study uses genre analysis as the technique that enables the researcher to study thesis abstracts as a genre. A genre means "a recognizable communicative event characterized by a set of communicative purpose(s) identified and mutually understood by the members of the professional or academic community in which it regularly occurs" (Bhatia, 1993:13). In this case, the communicative purpose(s) that shapes and gives internal structure to the master's thesis abstracts written by Indonesian EFL graduate students of English Language Education, Palangka Raya University were analyzed to find the rhetorical patterns used by the abstracts' writers.

Seventeen thesis abstracts written in 2010-2012 by Indonesian EFL graduate students of English Language Education at Palangka Raya University were purposively taken as the data of the study. The abstracts were selected based on certain criteria and then analyzed using a number of steps. The first step is examining the moves of the master's thesis abstracts by identifying the general rules of the overall surface structure format of the thesis abstracts using the model of analyzing the rhetoric or generic structure of the abstracts adopted from Samraj's (2002). This model consists of five moves, e.g., Move 1Situating the Research, Move 2-Purpose, Move 3-Methods, Move 4-Results, and Move 5Conclusion. The identification and examination on the general rules of the overall surface structure format of generic structure of each abstract with the linguistic realization on each move was done by examining phrases, clauses, sentences, or paragraphs which carry the realization of a communicative purpose. In this study, a move is identified ranging from a phrase, a clause, a sentence or even a paragraph. After all moves are identified, the second step is to put the results of moves identification and examination employed on all abstracts into a table with their linguistic realization. Subsequently the occurrence of each move in the abstracts is identified and then presented into a table. Then their frequency of occurrence are calculated to observe the obligatory and optional moves employed on the abstracts, as well as to describe the moves sequences/patterns which tend to be preferred to apply by the abstract writers in their abstract composition. The third step is examining the step(s) on each move by identifying the phrases, clauses, sentences, or paragraphs that carry the step(s) based on a particular function of the rhetoric or generic structure of the abstracts. 


\section{RESULT}

Based on Samraj's (2002) model, the rhetoric of seventeen abstracts were analyzed and the findings show that there are only three of 17 abstracts (17.65\%) which contain all five moves, while the other abstracts are composed using four or three moves. The frequently used moves or the obligatory moves in the abstracts (as presented in Table 1) are Move 2 Purpose (100\%), Move 3-Methods (100\%), and Move 4-Results (94.12\%) whereas Move 1-Situating the Research (29.41\%) and Move 5-Conclusion (64.70\%) are optional.

Table 1: The Frequency of Each Move Occurrence in the Abstracts

\begin{tabular}{lcc}
\hline \multicolumn{1}{c}{ Moves } & $\begin{array}{c}\text { Number of } \\
\text { Abstracts }\end{array}$ & Frequency of Occurrence \\
\hline Move 1-Situating the Research & 5 & $29.41 \%$ \\
\hline Move 2-Purpose & 17 & $100 \%$ \\
\hline Move 3-Methods & 17 & $100 \%$ \\
\hline Move 4-Results & 16 & $94.12 \%$ \\
\hline Move 5-Conclusion & 11 & $64.70 \%$ \\
\hline
\end{tabular}

The M2-M3-M4-M5 or PMRC patterns tend to be the most often sequence applied in the abstracts. The other sequences of moves employed in the abstracts are M1-M2-M3M4-M5 or SPMRC, M1-M2-M3-M4 or SPMR, M2-M3-M4 or PMR, and there is only one move pattern of M2-M3-M5 or PMC found. The frequency of occurrence of each moves pattern is presented in Table 2.

Table 2: The Occurrence of Moves Pattern Employed in the Master's Theses Abstracts

\begin{tabular}{lll}
\hline \multicolumn{1}{c}{ Move Patterns } & \multicolumn{1}{c}{ Number of Abstracts } & Percentage \\
\hline M1-M2-M3-M4-M5 (SPMRC) & $04,15,17$ & $3(17.65 \%)$ \\
\hline M1-M2-M3-M4 (SPMR) & 13,16 & $2(11.76 \%)$ \\
\hline M2-M3-M4-M5 (PMRC) & $02,03,06,07,09,10,12$ & $7(41.18 \%)$ \\
\hline M2-M3-M4 (PMR) & $01,05,08,14$ & $4(23.53 \%)$ \\
\hline M2-M3-M5 (PMC) & 11 & $1(5.88 \%)$ \\
\hline \multicolumn{1}{c}{ TOTAL } & 17 & $17(100 \%)$ \\
\hline
\end{tabular}

Having done more specific analysis, interesting moves sequences are identified. Commonly, the rhetorical moves in abstracts have linear order of M1-M2-M3-M4-M5. However in this study, some addition, embedment or deletion of one or two moves in the abstracts composition is found and several moves have reordering and repeating sequences. The variation of the rhetorical moves sequences are shown in Table 3.

Table 3: The Moves Sequence in Each Subject/Abstract

\begin{tabular}{cll}
\hline NO & SUBJECT/ABSTRACT & MOVE PATTERNS \\
\hline 1. & $01 / \mathrm{ESR} / 2010$ & M2-M3-M4 \\
\hline 2. & $02 / \mathrm{RM} / 2010$ & M2-M3-M4-M5 \\
\hline 3. & $03 / \mathrm{BPP} / 2010$ & M2-M3-M4-M5 \\
\hline 4. & $04 / \mathrm{MNN} / 2010$ & {$[\mathrm{M} 2 / \mathrm{M} 1]-\mathrm{M} 3-\mathrm{M} 4-\mathrm{M} 5$} \\
\hline
\end{tabular}




\begin{tabular}{cll}
\hline 5. & $05 / \mathrm{YR} / 2010$ & M2-M3-M4 \\
\hline 6. & $06 / \mathrm{LS} / 2010$ & M2-M3-M4-M5 \\
\hline 7. & $07 / \mathrm{SS} / 2010$ & M2-M3-M4-M5 \\
\hline 8. & $08 / \mathrm{Sy} / 2010$ & M2-M3-M4 \\
\hline 9. & $09 / \mathrm{ET} / 2010$ & M2-M3-M4-M5 \\
\hline 10. & $10 / \mathrm{NNT} / 2010$ & M2-M3-M4-M5 \\
\hline 11. & $11 / \mathrm{MSU} / 2010$ & M2-M3-M5 \\
\hline 12. & $12 / \mathrm{FAO} / 2011$ & M2-M3-M4-M5 \\
\hline 13. & $13 / \mathrm{DS} / 2011$ & {$[\mathrm{M} 2 / \mathrm{M} 3]-\mathrm{M} 1-[\mathrm{M} 2 / \mathrm{M} 3]-\mathrm{M} 4$} \\
\hline 14. & $14 / \mathrm{TW} / 20$ & M3-M2-M3-M4 \\
\hline 15. & $15 / \mathrm{TE} / 2011$ & M1-M2-M3-M4-M5 \\
\hline 16. & $16 / \mathrm{MP} / 2012$ & M1-[M3/M2]-M3-M4 \\
\hline 17. & $17 / \mathrm{Yt} / 2012$ & M1-[M3/M2]-M1-M3-M4-M5 \\
\hline
\end{tabular}

The results in Table 3 show that the linear/conventional sequence of moves (M1M2-M3-M4-M5) can be seen only in abstract 15. The other two data (abstracts 04 and 17) are also composed of five moves; however embedding moves occur in the two abstracts. In abstract 04, M2 is embedded within M1 whereas in abstract 17, M3 is embedded within M2 and moves reordering with the insertion of M1 in the moves sequences are done. The square brackets show the embedding of the subordinate move(s) within the major move. Embedding move also occurs between M2 and M1, and M2 and M3.

Meanwhile the most common move pattern is M2-M3-M4-M5 (without applying M1). Of the 17 abstracts, seven abstracts $(02,03,06,07,09,10$, and 12) employ this move pattern. The deletion of M5 occurs in six abstracts $(01,05,08,13,14$, and 16). The move reordering pattern emerges in abstracts 13 and 17 by positioning M1 not only in the beginning of the move sequence but also in the middle position of moves patterns. The move deletion of M4 is only found in abstract 11.

\section{DISCUSSION}

In an attempt to have further description on the rhetoric of master's thesis abstracts employed by Indonesian EFL graduate students of English Language Education at Palangka Raya University, the following discussion is on the subject of the strategic function of each move as well as the step(s) that support the move.

\section{Move 1-Situating the Research}

Move 1-Situating the Research is the introduction move which is usually placed in the initial position and used by the writer to indicate the interest or importance of the research. Based on Samraj's (2005) observation, this 'introduction' move is the most frequent and mandatory element in abstracts. For that reason, Samraj (2009) states that this move may have a persuasive or neutral contextualizing function. As a persuasive function, commonly, M1 is used to stimulate the readers' interest by indicating a problem noticed by the research writer, or a limitation or gap found in the previous research. Meanwhile M1 has a neutral contextualizing function when it provides the readers with the background knowledge or theory used as the base of the research.

However, the findings of this study is not in line with Samraj's (2005) statement as out of 17 abstracts, there are only 5 abstracts (29.41\%) using M1 in the moves sequence. 
The application of M1 is only found in abstracts $04,13,15,16$, and 17. This is also different from Djuwari's (2009) findings which concludes that all of the abstracts he analyzed in his study, 36 (80\%) abstracts use Move 1. Thus, it can be said that the abstract writers in this study are likely to lack for awareness of the important function of Move 1 has in the abstract composition.

To realize the communicative purpose of Move 1, two steps are used by the abstract writers to support the M1 persuasive and neutral contextualizing function. Step 1Presenting the problem(s) of the study is employed in abstracts 04 and 15, whereas Step 2Making statements about theory or knowledge as the base of the study is applied in abstracts 13 and 16. The combination of the two steps is used in abstract 17 as shown in Excerpt 1:

1. There are three major problems related to writing instruction at the English Education Study Program of the University of Palangka Raya. The problems are related to limited sources of printed materials that results in the lack of input in the form of knowledge or experiences, the activity which is mostly teacher-centered, and feedbacks towards the students' writings. These three problems affect students to write in English, especially when dealing with academic essays [M1-Situating the Research]. The researcher then interested to conduct an experiment [M3Methods] by using short stories of literary works in the treatment in order to see whether there are significant effects of using the short stories to the students' scores [M2-Purpose].

Short stories of literary works were used in this study as they offer various topics that attract students' interests. Literary works, in this case, short stories, are effective sources for language learning as students can interpret and react to them personally. Moreover, discussing and sharing opinions about the stories also encourage students to be active therefore the class atmosphere becomes mostly students-centered. At last, by having short stories of literary works as their sources, students can produce meaningful writings as they can discuss good values or uniqueness that they can find in the stories [M1-Situating the Research]. [17/Yt/2012]

It is apparent that to attract the readers' interest, the abstract writer used the identification of problems she noticed in the teaching and learning of Writing in her institution as the opening of her abstract. She persuades the readers of the importance of the research to be presented to solve the problems by highlighting the purpose and method of conducting the research in the next moves [M3/M2] of the abstract. Then to make the abstract more accessible to the readers, she provides the readers with the statement about the knowledge or theory she used as the base of her research.

Concerning the moves sequence, an exceptional sequence of moves is identified in the aforementioned excerpt in which M1 is not only placed in the initial order but also in the middle position of the moves sequence [M1-[M3/M2]-M1-M3-M4-M5]. This is similar to abstract 13 that also put M1 in the middle position of the moves sequence. A more noteworthy structure related to moves sequence is noticed in Excerpt 2, in which an embedment occurs between M1 and M2.

2. The problem of this study was how are the junior high school English teachers in East Barito Regency's competence in genre-based texts [M1-Situating the Research] /with the objective was to find out the competence of East Barito Regency junior high school English teachers in genre-based texts [M2-Purpose]. [04/MNN/2010]

In this sequence, M2-Purpose is embedded in the major move, M1-Situating the Research. The writer of the abstract uses Step 1-Presenting the problem(s) of the study of 
M1 as the opening of the abstract then attaches the purpose of the study into M1. In this case, the writer seems to persuade the readers that there is a problem found related to the junior high school English teachers' competence in mastering genre texts, so a research on it has to be conducted. This persuasion is supported by embedding the purposive statement into the introduction statement. Apparently, the embedment is done to achieve a brief and subtle abstract writing. However, as the way the writer arranges the opening and purposive statements only by reversing the sentences, the persuasion seems to lack for evidence to convince the readers about what kind of problems actually faced by the English teachers in the research. Moreover, there is no more supporting explanation describing the background knowledge of why it is important for the junior high school English teachers to master genre texts.

Taking the aforementioned findings into account, it can be concluded that Move 1 has a significant function in the abstract writing. It is used to introduce the topic or subject of the research. This is in accordance with Rathbone's (1985) statement that an abstract should introduce the topic of the research, as well as the opinions from Brinegar and Skates, 1983; Herbert, 1990; Kilborn, 1998; Samraj, 2002; and Swales, 1990 which state that an abstract should express the topic or scope of the research. Notwithstanding of the important function of Move 1 has in the abstract writing, practically to achieve the communicative purpose of the abstract, the abstract writer may freely choose and arrange what move she/he will first place and highlight in the moves sequence.

\section{Move 2-Purpose}

In this study, Move 2-Purpose is an obligatory move used to indicate the purpose of the research. This move occurs in all abstracts, however in the order of the moves patterns; this move has various positions. There are 13 (76.47\%) abstracts that place this move in the initial position of the linear moves sequence and use it as the opening move. The initial position of this move is found in abstracts $01,02,03,04,05,06,07,08,09,10,11,12$, and 13. However there occurs an embedment in abstracts 04 and 13. In abstract 04, M2 is incorporated into M1 (as the major move) and positioned in the beginning of the abstract. Whereas in abstract 13, M2 is embedded into the major move of M3 and interestingly, this embedment occurs twice in the initial and middle position. In this regard, compared with Move 1, Move 2 is likely to be more preferred by the abstract writers to initiate and introduce the abstracts to the readers.

The other position of M2 in the moves sequence is in the middle position. The middle position of this move is found in four (23.53\%) abstracts (Abstracts 14, 15, 16 and 17). In abstract 14, M2 is placed in linear order after M3 and before M3 and M4; while in abstract 15, M2 is linearly positioned after M1 and before M3, M4, and M5. In abstracts 16 and 17, there is an embedment between M2 as the major move and M3 and this embedding move of $\mathrm{M} 2$ is placed in the middle position of the move sequence.

To realize the communicative purpose of this move, according to Van Bonn and Swales (2007), usually the writers use either purposive form (Step 1a): outlining the purpose of the study, or descriptive form (Step 1b): announcing/ presenting the present research. Step 1a is marked by purposive statements containing the explicit use of lexical 
signals such as objective, aim, goal, or purpose. Whereas, announcing/presenting the present research (step 1b) is used to point out the description of the features of the research.

The findings of this study show that the purposive M2 (Step 1a) is found in 5 (29.41\%) abstracts. The use of this step is characterized by the presence of a purposive lexical item such as the objective, the aim, and the purpose as shown in Excerpt 3:

3. The purpose of this study was to improve the students' ability on writing narrative text, students' motivation, and social interaction through the implementation of STAD of Cooperative Learning Method. [15/TE/2011]

In Excerpt 3, the abstract writer initiates this step by employing a general statement of purpose in the form of subject noun phrase 'the purpose of this study' followed by linking verb 'was' plus a more precise purposive statement 'to improve the students' ability...'

In contrast, the descriptive M2 (Step 1b) is likely to be more preferred by the abstract writers. This step is applied in $11(64.71 \%)$ abstracts. Utilizing this step, the abstracts writers tend to describe the main features of the research using a head noun as a subject that refers to the study/research with the demonstrative pronoun 'this' or the definite article 'the', followed by the main verbs in passive form (such as was conducted, is intended, was aimed) plus the infinitive verbs (such as to investigate, to describe, to find out, to know) then added by the more precise purposive statement as can be seen in Excerpt 4:

4. This study was conducted to investigate the effect of context clues on reading comprehension in explanation text, the effect of student's gender on reading comprehension in explanation text, and the effect of context clues and students' gender on reading comprehension in explanation text of the eleventh grade students of SMA Negeri 4 Palangka Raya in academic year 2009/2010. [03/BPP/2010]

In several abstracts, a standard descriptive form with the use of animate subject refers to the researcher/writer is identified as shown in Excerpts 5, 6, and 7:

5. In this study, the writer is intended to find out the language used by the English teachers in writing the narrative text through text engineering.

[10/NNT/2010]

6. In this study, the writer interested to find out the effects of context clues and gender on reading comprehension of analytical exposition. This study was also conducted to find out the effect of context clues on reading comprehension. Ans, it was also conducted to find out the effect of students' gender on reading comprehension. [11/MSU/2010]

7. The researcher was then interested to conduct an experiment by using short stories of literary works in the treatment in order to see whether there are significant effects of using the short stories to the students' scores.

[17/Yt/2012]

Interestingly, the use of the two options of the step in one abstract (5.88\%) is identified as shown in Excerpt 8:

8. This observational study [M3-Method] focused on ESA strategy used by teachers when teaching English/with the aim to investigate the variation and the pattern of the elements in teaching strategy [M2-Purpose, Step 1a]. The major theory were taken from.... [M1-Situating the Research]. 
The study used a qualitative method [M3-Method]/to investigate the variation and the pattern of the ESA elements spreading in a sequence in teachers' strategies. [M2-Purpose, Step 1b]....[13/DS/2011].

In Excerpt 8, the purposive M2 is embedded into the major move of M3 and used as the opening and introduction of the abstract. After the placement of M1 in the next order of the embedding move, then it is followed by the embedment of the descriptive M2 into M3.

However having a closer look at the features of descriptive M2, it is noticed that the ineffective realization of general statements of purpose occur in several abstracts. The general statements of purpose are indirectly stated but developed by using a variety of supporting sentences turning around the main purposive theme. Such as in Excerpt 4, instead of employing the direct purposive statement 'This study investigates...' the abstract writer adds the passive form as the main verb in the statement. Another example is in the purposive statement of abstract 12 'This study was aimed to describe...'. Instead of realizing M2 using Step 1a which directly focuses on the purpose statement like in 'The aim of this study was to describe...', or Step $1 \mathrm{~b}$ which descriptively focuses the features of the study like in 'This study describes...', the abstracts writers tend to combine the two options in M2. The more noteworthy finding is there found redundancy on the use of purposive statement in this move as shown in Excerpt 6. Move 2 in Excerpt 6 is realized repeatedly using the similar descriptive form of general statement of purpose followed by the different kinds of more precise purposive statements. This kind of redundancy also occurs in abstracts 07 and 11.

Obviously, the aforementioned findings show that in realizing M2, the abstract writers are still probably influenced by their first language (Indonesian) rhetorical pattern. The findings is in line with Basthomi's (2006b) preliminary investigation on the rhetoric of article abstracts written by Indonesians which says that Indonesians writing abstracts in English go toward "their own place" of Indonesian rhetoric. This fact also supports Kaplan's (1966) theory which states that rhetoric is not universal but varies from culture to culture and even from time to time within a given culture, as well as Connor's (1996:5) opinion which says that the linguistic and rhetorical conventions of the first language interfere with writing in the second language.

\section{Move 3-Methods}

In this study, this move occurs in all abstracts. This obligatory move contains some description of how the research/study is actually conducted to achieve the objectives of the study. It usually provides information about the methods or the research design, the data, the subjects of the study, the criteria, the instruments, the setting, procedures of data analysis, and etc. Usually, this move is placed in the middle position after M1/M2 and before M4/M5. However in two abstracts (abstracts 13 and 14), this move is used as the opening of the abstracts. In abstract 13 (as shown in Excerpt 8), this move is merged with M2 and in the moves sequence, this merger occurs twice in the initial and middle positions. In abstract 14, M3 which contains the information of the setting and criteria of the subjects 
of the study is placed in the initial position of the abstract. It is followed by the occurrence of M2 in the next order and then subsequently added by the information of the data analysis technique. The application of this move can be seen in Excerpt 9:

9. The study of this thesis was held in the Grade Seven of SMP Muhammadiyah Palangka Raya. The characteristics of the subjects are (1) graduated from SD and only a few are from madrasah. (2) they never studied English at SD/Madrasah, and (3) they entered the Islamic SMPs because they were not accepted in state schools (Step 2). [M3-Methods]

Besides due to complete the requirement of finishing study in the Graduate Program of English Education, The University of Palangka Raya, it is also intended to know:.... [M2-Purpose]

This study uses ANCOVA (Analysis of Covariance) to analyze the data.... (Step 3) [M3Methods] [14/TW/2011]

To realize the communicative purpose of this move, the abstract writers tend to employ one or more of the following steps:

1. Step 1-Describing the method of the study or the research design. To make the readers easily understood of how the research/study is conducted, the abstract writers tend to include the method of the study or the research design, therefore this step is applied in most of the abstracts. The application of this step is always used in combination with the other step(s) of this move. However, the occurrence of this step is not always linearly put in the beginning of M3; but it may also exist after and before Step 2 or between Step 2 and Step 3. The following excerpts illustrate the occurrence of this constituent step in different orders:

10. The study was conducted by adopting the Classroom Action Research design (Step 1). The data needed in this study was collected through a pair of test (pre test and post test) and classroom observation (Step 2). Descriptive and inferential statistics were used to analyze the data by determining the Mean score and Percentage of students who were able to reach the targeted score (Step 3). [15/TE/2011]

11. The data needed in this study were a test and a questionnaire. The test had 100 items in the form of multiple choice questions. There were 10 answer sheets. The test was consisted of genre-based texts of descriptive, report, narrative, recount and procedure. The questionnaire consisted of 12 questions, related to the teachers' understanding on genre-based text and teachers' identity (Step 2).

In running this study, the writer used descriptive method (Step 1). The sample of the study was the English teachers from Mentawa Baru Ketapang and Baamang districts, in East Kotawaringin Regency. The number of sample in this study was 10 teachers from five state schools and five private schools (Step 2). [06/LS/2010]

12. The population of this study was the $11^{\text {th }}$ grade students at SMA Negeri 4 Pahandut Palangka Raya in academic year 2009/2010.

In order to collect the data needed, the writer used test as instrument. In this study, the instrument consisted of 30 items of three texts with context clues definition and synonym in reading comprehension test (Step 2).

In this study, the writer used experimental method (Step 1). The data were processed and analyzed based on these steps: giving the treatment, coding, scoring, tabulating, analyzing the data by using ANOVA (computerized programs named SPSS version 15), and taking the conclusion based on the result of the data analysis (Step 3). [09/ET/2010] 
In Excerpt 10, Step 1 is placed linearly before Step 2 and Step 3; in Excerpt 11, this step is placed after and before Step 2; and in Excerpt 12, Step 1 is positioned between Step 2 and Step 3.

2. Step 2-Describing the research procedures. It may contain the information of the research instrument, the data/sample/population/subject/participants/setting of the research, the criteria of subjects of the study, and the data collection. This step may also occur in various positions (in the beginning, middle or final order) in most of the abstracts and it is commonly used in combination with Step 1 and Step 3. Yet, interestingly two abstracts used only this step to realize the communicative purpose of M3 as shown in Excerpts 13 and 14:

13. The data obtained through one hundred multiple choice items test of descriptive, report, narrative, recount, and procedure texts, while questionnaires related to the teachers' background or identity. The subject of the study was 13 English teachers of junior high schools in the districts of Kahayan Hilir, Maliku, and Jabiren Raya Pulang Pisau Regency. [02/RM/2010]

(Step 2)

14. ....The subjects of the study were the English teachers who have graduated from PPKKG (Program Peningkatan Kualifikasi dan Kompetensi Guru) University of Palangka Raya. The number of subjects are six English Teachers who come from Palangka Raya, as in this study they were asked to recreated text of Cinderella (Step 2).

The procedure of collected the data were: (1) Telling the story of Cinderella to the teachers, (2) Asking the teachers to recreate the story, (3) Collecting the teachers' worksheets, (4) Analyzing the texts which contain the elements, such as language features, social function, and generic structure through lexico-grammar and discourse semantics analysis to have the means of textx (ideational, textual, interpersonal meanings). (Step 2) [07/SS/2010]

Step 2 employed in Excerpt 13 and 14 merely contain the information of the data collection and the subject of the study without any other explanation such as the methods used in the study or how the data of the study are analyzed.

3. Step 3-Describing data analysis procedure (recounting data analysis procedures). This step functions to specify which procedures or techniques are used to analyze the data. This step is also combined with one or more other step(s) of M3. Usually this step is mentioned in the last place, but in the following excerpt, it is placed in the middle order:

15. The method used in this study is research and development study, which was done by observing the classroom activity, analyzing the student's English demand based on synectic model and developing the result to construct learning activities in synectic model (Step 1). The data were processed through the following steps: observing, classifying, analyzing questionnaires, and counting the percentage of the data and putting the data into general conclusion based on criteria which had been determined (Step 3). The subject of the study was the fifth grade students of SDN Percobaan Palangka Raya. The numbers of the students were 30. In order to get the result of the study, the writer constructed checklistvtable, test and questionnaires (Step 2). $[08 / \mathrm{Sy} / 2010]$

Having a closer look at the steps discussed in this move, it seems that in arranging and organizing the steps to realize the communicative purpose of this move, the abstract writers probably do not pay attention well to the order of occurrence of the steps. Commonly, to make the readers easily understand on the process of how the research/study 
is conducted, the steps in M3 will be well-delivered in a good construction and organization. The ideas in the steps of this move are usually presented orderly from the general up to the more specific ones. However, in this move, they are stated abruptly from one idea to another. Accordingly, the result being that the steps realized in such a way can be particularly disadvantageous for the readers. Although practically the abstract writer seems to have freedom in arranging and organizing the moves and steps in his/her writing, to make the abstract writing is more understood and accessible for the readers, the abstract writer should be able to produce good informative, non-misleading, and well-organized sequence of moves and steps.

\section{Move 4-Results}

This move is used to announce the principal findings or the results of the research, as stated by Salager-Meyer (1992:105) that "It mentions the most salient and striking findings". It may also include a description of the accomplishments of the study or the presentation of argument as can be seen in Excerpt 16 and 17:

16. The significance value of the data of posttest in the Control group was 0.685 and in the Experimental group was 0.015 . As $0.015<0.05$, it means that Ho was rejected and Ha was accepted. Therefore, in the significance level of 0.05 there is a significant difference of students' achievement taught to write opinion essays by responding to short stories and achievement of those taught in conventional writing class. [17/Yt/2012]

17. In terms of planning and preparing the instruction, the teacher has planned and prepared the instruction before he/she teaches. His/her preparation simply can be seen from classroom preparation, teaching media, classroom activities and all aspects needed in setting the lesson plan. Related to the implementation of the plan in teaching learning process, the teacher consistently applies the lesson plan, teacher often makes some modifications when the students can not do what the teacher ask them to do. This often occurs in Building knowledge of the field. In terms of assessing the students' does not get any information or feedback from the student except their performance throughout the lesson. However, teacher actually need the feedback in order to evaluate the effectiveness of teaching learning process to arrive at the instructional goals. Modeling of the text. This stage is critical for the students' critical literacy for it involves analysis and discussions about how and why examples of a particular genre are organized to make meaning. Joint construction of the text, In this stage, students write several drafts in several sessions, at least three sessions, to make them aware that writing is a recursive process, and not a one shot activity. Independent construction of the text, the students write independently constructed text in several meetings with several drafts before they come to a neat final draft. [16/MP/2012]

Commonly, to initiate this move, the abstract writers tend to apply the subjects that refer to writers' own work research outcome such as "the result, the result of this study, the findings of the study" (as in Excerpt 18) or the inanimate subject 'it' (as in Excerpt 19). These subjects occur mostly with the verbs 'show', 'reveal' or linking verb 'Be':

18. The findings of the study were: firstly, the variations of the ESA of the two teachers were different each other. Teacher A placed the ESA in sequence was in balance, while, teacher B, on the other hand, tended to order the ESA more on the Study and Activation elements; secondly, the pattern of the ESA was almost all Patchwork Sequence, in addition to Straight Arrow Sequence. The Patchwork pattern was varied in sub variation. [13/DS/2011]

19. By applying synectic model, it showed that the average students' test result was 77.16 (good level). Based on supporting data from the questionnaire of the students' perception toward synectic showed that the students' awareness on creativity learning model was concluded that 
$53.3 \%$ students prefer to be creative as creating something new and making product, $46.6 \%$ students prefer that synectic is very helpful, $96.6 \%$ students showed that synectic gives more motivation in learning English, 53.3\% prefer funny picture and media makes learning easier, $70 \%$ students have the creation to be expressed in English, $96.6 \%$ students prefer that synectic helps them to show their idea, expression and creation. [08/Sy/2010]

In the moves sequence, this move is often positioned linearly before M3 and after M5, and in six abstracts, it is used as the closing or the last move of the abstracts. This move is also categorized as the obligatory move which has $94.12 \%$ frequency of occurrence. It does not have $100 \%$ frequency of occurrence as its exclusion is found in one abstract (Abstract 11) as shown in Excerpt 20:

20. In this study, the writer interested to find out the effects of context clues and gender on reading comprehension of analytical exposition. This study was also conducted to find out the effect of context clues on reading comprehension. Ans, it was also conducted to find out the effect of students' gender on reading comprehension. [M2-Purpose]

The population of this study was eleventh grade IPA students of SMA Negeri 1 Palangka Raya in academic year 2009/2010. Test in form of multiple-choice questions was us as two kinds of treatment ; They were in form context clus with definition (X1), and context clues with synonym (X2). [M3-Methods]

The writer used experimental method on this study. The data were analyzed by using Parametric statistic of Two-Way ANOVA (computerized programs named SPSS version 15) and the data were normally distributed and homogeny. [M3-Methods]

Base on the result of the study, it can be conculed that there was no significant interaction effect of context clues and gender on reading comprehension, that there was significant effect of context clues on reading comprehension, and that there was no significant effect of gender on reading comprehension. [M5-Conclusions]

In addition, the writer suggested for the English teacher can improve and variation on their teaching style with using context clues for solve the students problem be side using an authoritative dictionary to find their meaning. [M5-Conclusions] [11/MSU/2010]

An interesting point to note in Excerpt 16 is the absence of Move 4-Results in the moves sequence of the abstract. The features of this move (such as the use of subjects which refer to writer's own research outcome and the occurrence of the common verbs indicated this move) discussed previously are not identified in this abstract. This may be due to the fact that the abstract writer has difficulties in distinguishing between the Results and Conclusion moves. The use of the phrase "Base[sic] on the result of the study" may have ambiguous meaning as it may refer to the report on the results of the study that has been previously mentioned (which actually has not been stated yet by the abstract writer). In addition, the next sentence "it can be conculed[sic]" emphasizes that the information carried on in this move can be interpreted as a proposition or a conclusion that is reached from the discussion of the results of the study. The grammatical errors on several words make worse of this ambiguity. This fact is in line with the statement of Martin (2003:39) which notes that "This indicates that the division between the Results and Conclusion units is not always clear".

To realize the communicative purpose of this move, three steps are used:

1. Step 1-Reporting and describing the specific results. This step can stand by itself as there are six abstracts that apply only this step to realize their communicative purpose of 
M4 (as shown in Excerpt 18 and19). This step may also be applied with the other steps of M4 such as combined with Step 2 and Step 3 (as shown in Excerpt 16), combined with Step 3 (as shown in Excerpt 17) or combined with Step 2 as shown in the following excerpt:

21. The result of this study shows that Test of Between-Subjects Effects shows the Significant value of gender was .341 [Step 1], it could be said that there was no significant effect of gender on students' reading comprehension [Step 2]. There was no significant effect of context clues on students' reading comprehension that indicated by the significant value .506 [Step 1]. The significant value of gender together with context clues was .662, it could be said that both gender and context clues had no significant effect on students' reading comprehension of the $11^{\text {th }}$ grade students at SMA Negeri 4 Pahandut Palangka Raya in academic year 2009/2010 [Step 2]. [09/ET/2010]

2. Step 2-Interpreting the results. This step is used to explain the meaning of the result of study. It is always employed in combination with the other steps (Step 1 and 3 as shown in Excerpt 16) or only with Step 1 (as can be seen in Excerpt 21). It is indicated by the occurrence of 'Impersonal It' such as 'It means/meant (that)' or 'It could be said'.

3. Step 3-Commenting the results. The abstract writers use this step to express their opinion in relation to the description of result of the study. This step is employed in combination with the other steps of M4, and indicated by the use of conjunction such as 'however, but, therefore' to initiate this step. The application of this step combined with the other step(s) can be seen in Excerpt 16 and 17.

\section{Move 5-Conclusion}

This optional move is applied in $11(64.70 \%)$ abstracts. Utilizing this move, the abstract writers try to draw the inferences of the research or summarize the implications drawn from the results (Step 1), or point to application or wider implications (Step 2), or state recommendation for further research (Step 3). In realizing the communicative purpose of this move, each step can stand by itself (as shown in Excerpt 22, 23, and 24), or may be used in combination with the other step(s) (as can be seen in Excerpt 25 and 26).

22. The teachers' background in education and experience in teaching English had influenced of the teachers' competency in genre-based texts, that they had good level category (Step 1). [06/LS/2010]

23. ....Therefore, the English teachers are expected to have enough training in order to enhance the competence especially in writing skill (Step 2). [10/NNT/2010]

24. The writer suggests for the next researcher who interest in this study could observe the students related with the difficult words that they have underlined and why they considered those words are difficult (Step 3). [03/BPP/2010]

25. Finally, based on the result of the study, the implementation of STAD of Cooperative Learning Method can be employed to improve the students' ability on writing narrative text, the students' motivation on learning English and the students' social interaction (Step 1). Based on that case, there are some suggestions given as follows: (1) The STAD of Cooperative Learning can be applied as an alternative solution for students' problem in learning English. (2) The STAD of Cooperative Learning Method can be employed and practiced to improve students' writing ability, motivation and social interaction. (3) The STAD of Cooperative Learning Method can be used as an effective method by the teacher in teaching English writing, especially for narrative text and to solve the students' problem on English writing subject (Step 2). [15/TE/2011] 
26. Based on the result of the study, some suggestions are given. First, the English teachers are hoped to be more concern about the importance of social and culture context in influencing the writer's (the students') writing processes, and the language function itself through Systemic Funtional Linguistics. Second, it is hoped that the result of this study can enhance the students to be able to learn about the language (lexico-grammar and discourse-semantics), and they can learn about their social/ situational and culture. Third, the government of Palangka Raya, through educational institution like Kepala Dinas Pendidikan, Pemuda dan Olahraga is hoped to give more attention in improving the educators' competency, especially for teachers by holding some training related to genre-based writing using Systemic Functional Linguistics (SFL) approach (Step 2). Third, for further research, it is hoped that this study will give contribution to conduct other research related to Systemic Functional Linguistics approach (Step 3). [12/FAO/2011]

\section{CONCLUSION}

The findings of the study show that the rhetorical pattern of thesis abstracts written by Indonesian EFL graduate students of English Language Education, Palangka Raya University are in line with those of Samraj (2002) which show that three textual spaces: M2-Purpose, M3-Methods, and M4-Results are compulsory while the other two moves (M1-Situating the Research and M5-Conclusion) are optional. Further examination on the rhetorical patterns reveals that the abstracts mostly follow the pattern of PMRC or M2-M3M4-M5 (41.18\%). The other rhetorical patterns applied are M1-M2-M3-M4-M5 or SPMRC (17.65\%), M1-M2-M3-M4 or SPMR (11.76\%), M2-M3-M4 or PMR (23.53\%), and M2-M3-M5 or PMC (5.88\%).

Each move of the abstract is realized using at least one step or more. However, a great deal of first language rhetorical pattern influence is discovered among the moves or the steps forming each move. This can be seen in several occurrences of redundancy use of steps particularly in M2, reordering or non-linear patterns of steps mostly the steps in M3, the overlap function between moves especially between M4 and M5, the low occurrence of M1, and the repeated use of embedding moves particularly the embedment of M2 and M3. Furthermore, the poor mastery of the abstract writers on their second language (proven by the existence of many grammatical errors, spelling errors, also lexical errors), which is unfortunately in the meantime is not included as the focus of the study, makes the rhetoric of thesis abstracts more inaccurate and unclear.

The findings of the study also bear some pedagogical implications to help particularly the Indonesian EFL graduate students of English Language Education, Palangka Raya University have better understanding and mastery on the rhetorical conventions of English as their second language. In relation to the teaching of English writing particularly academic writing, the lecturers/teachers need to consider incorporating the knowledge of English rhetorical conventions in their teaching. Furthermore, the findings also serve as valuable information for the thesis advisors to improve their attempts in supervising the students' writing. As well, the findings are able to give contribution to wiping out the weaknesses and improving the existing knowledge that is already included in the guide book of writing a proposal and a thesis used by the graduate students of English Language Education at Palangka Raya University. 


\section{REFERENCES}

Anderson, K., \& Maclean, J. 1997. A Genre Analysis Study of 80 Medical Abstracts. Edinburgh Working Papers in Applied Linguistics, 8: 1-23.

Basthomi, Y. 2006a. The Rhetoric of Research Article Introductions Written in English by Indonesians. Doctoral Dissertation: Malang: State University of Malang.

Basthomi, Y. 2006b. The Rhetoric of Article Abstracts: A Sweep through the Literature and a Preliminary Study. Bahasa dan Seni, 34(2): 174-189.

Basthomi, Y. 2007. Contrastive Rhetoric, Discourse, and Genre Analysis: Methodological Issues. Bahasa dan Seni, 35(2): 133-146.

Basthomi, Y. 2008. Acknowledging as/Is Respecting: Interlanguage Discourse of Thesis Acknowledgements Section. Paper presented at The 2008 LSP Conference and General Meeting on World Englishes and Second Language Teaching and Learning, the University of Sto. Tomas, Manila, 28-30 April 2008.

Bhatia, V.1993. Analyzing Genre: Language Use in Professional Settings. London: Longman.

Connor, U. 1996. Contrastive Rhetoric: Cross-Cultural Aspects of Second-Language Writing. Cambridge: Cambridge University Press.

Djuwari. 2009. The Genre Analysis of International Conference Paper Abstracts. Unpublished Doctoral Dissertation. Malang: State University of Malang.

Dong, Hai-lin. \& Xue, Huan. 2010. Generic Structure of Research Article Abstracts. Cross-Cultural Communication Journal, 6(3): 36-44.

Dudley-Evans, T. 1987. Introduction to Genre Analysis and ESP. ELR Journal, 1: 1-9. Birmingham: University of Birmingham, English Language Research.

Flowerdew, J. 2002. Academic Discourse. United Kingdom: Routledge.

Graetz, N. 1985. Teaching EFL Students to Extract Structural Information from Abstracts. In Ulign J. M and Pugh A. K. (eds) Reading for Professional Purposes: Methods and Materials in Teaching Languages, Leuven: Acco:123 - 135.

Holmes, R. 1997. Genre Analysis and the Social Sciences: An Investigation of the Structure of Research Article Discussion Sections in Three Disciplines. English for Specific Purposes, 16(4): 321-337.

Hyland, K. 2000. Disciplinary Discourses: Social Interactions in Academic Writing. London, UK: Longman.

Hyland, K. 2002. Options of Identity in Academic Writing. ELT Journal, 56(4): 351-358.

Kaplan, R. B. 1966. Cultural Thought Patterns in Intercultural Education. Language Learning, 16, 1-20. http://dx.doi.org/10.1111/j.1467-1770.1966.tb00804.x

Kaplan, R. B. 1967. Contrastive Rhetoric and the Teaching of Composition. TESOL Quarterly, 1, 10-16.

Kaplan, R. B. 1972. The Anatomy of Rhetoric: Prolegomena to a Functional Theory of Rhetoric. Philadelphia: Center for Curriculum Development. 
Kaplan, R.B. 1987. Cultural Thought Patterns Revisited. In Writing across Languages: Analysis of L2 Text, Edited by U Connor and R.B. Kaplan, 9-21 Reading, MA: Addison-Wesley.

Martin, P. M. 2003. A Genre Analysis of English and Spanish Research Paper Abstracts in Experimental Social Sciences. English for Specific Purposes, 22(1): 25-43.

Melander, B., Swales, J. M., \& Fredrickson, K. M. 1997. Journal Abstracts from Three Academic Fields in the United States and Sweden: National or Disciplinary Proclivities? In A. Duszak (Ed.), Intellectual Styles and Cross-Cultural Communication. Berlin: Mouton De Gruyter.

Pho, P. D. 2008. Research Article Abstracts in Applied Linguistics and Educational Technology: A Study of Linguistic Realizations of Rhetorical Structure and Authorial Stance. Discourse Studies, 10(2): 231-250.

Salager-Meyer, F. 1990. Discoursal Flaws in Medical English Abstracts: A genre Analysis per Research and Text-type. Text, 10(4): 365-384.

Salager-Meyer, F. 1992. A Text-type and Move Analysis Study of Verb Tense and Modality Distribution in Medical English Abstracts. English for Specific Purposes, 11(2): 93-113.

Samraj, B. 2002. Introductions in Research Articles: Variations across Disciplines. English for Specific Purposes, 2: 1-17.

Samraj, B. 2005. An Exploration of a Genre Set: Research Article Abstracts and Introductions in Two Disciplines. English for Specific Purposes, 24(2): 141-156.

Samra, B. 2008. A Discourse Analysis of Master's Theses across Disciplines with a Focus on Introduction. Journal of English for Academic Purposes, 7, 55-67.

Samraj, B. 2009. Move Structure. Manuscript Submitted for Publication.

Swales, J. 1981. Aspects of Article Introductions. Birmingham, England: Language Studies Unit, the University of Aston.

Swales, J. M. 1990. Genre Analysis: English in Academic and Research Settings.

Cambridge, UK: Cambridge University Press.

Swales, J. M. 2004. Research Genres: Explorations and Applications. Cambridge, UK: Cambridge University Press.

Swales, J. M., \& Feak, C. B. 2009. Abstracts and the Writing of Abstracts. Ann Arbor, MI: University of Michigan Press.

Van Bonn, S., \& Swales, J.M. 2007. English and French Journal Abstracts in the Language Sciences: Three Exploratory Studies. Journal of English for Academic Purpose, 6(2): 93-108.

Wahab, A. 1986. Javanese Metaphors in Discourse Analysis. Unpublished

Ph.D. Dissertation. Champaign-Urbana: University of Illinois.

Zeng, Ya-jun. 2009. CARS Model in Analyzing the Introduction of Research Articles: An Example from the Field of Sports Science and Medicine. US-China Foreign Language, 7(3): Serial No 66. 